\title{
Optimization of Hydraulic Pressures in Kabacan Water District Pipe Network using h-Newton-Raphson Technique
}

\author{
M.P. Esberto, J.N.Orejudos
}

\begin{abstract}
The purpose of this study is to optimize the hydraulic pressures of a real-world water distribution network to protect the system with sustained adequate water supply. This novel approach is different from other published works in the sense that this study is intended to improve the water system of the Kabacan Water District (KWD) in Cotabato, Philippines. Yet, there are no previous scholarly efforts done with the KWD water system; thus, this study. The method used here is a modification of the methods used by references [4] and [14]. This optimization approach includes determination of control valve placement in the network to control the hydraulic pressures within the system. The proposed numerical model, with the EPANET Toolkit interface, resulted in a simpler and more accurate algorithm, which converges easily in all the 48 network models used in this study where the convergence is achieved from 9 to 74 iterations. This is an efficient and easy-to-use optimization solver for analyzing looped pipe networks even in large scale networks.
\end{abstract}

Keywords: Water Distribution System, Pressure Optimization, Control Valves, h-Newton Raphson, Looped Pipe Network.

\section{INTRODUCTION}

Recent studies have been focused on the analysis of water distribution networks under pressure deficient conditions. Many authors [1], [2], [3], [4], [5], [6], [7], [8] tried to investigate the optimal location of control valves to manage the pressures within the system. Development of a hybrid solver is widely practiced in the global research community to optimize the hydraulic pressures of a problematic water system. Under such circumstances, most scientific studies [9], [10], [11], [12], [13], [14] are focused on the development of a hydraulic solver shifting from conventional method (Demand Driven Analysis) to Pressure Demand Analysis. The latter is anchored on the nodal demand dependency on hydraulic pressures analyzed in a steady state hydraulic based procedure usually applied to looped pipe networks.

The same challenge confronts the Kabacan Water District (KWD) particularly at Zone B Water System located at Bgy. Bannawag, Kabacan, Cotabato (Fig. 1).

Revised Version Manuscript Received on 10 September, 2019.

M.P. Esberto, University of Southern Mindanao, Kabacan, Philippines. (Email: mdpesberto@usm.edu.ph)

J.N. Orejudos, Mindanao State University - Iligan Institute of Technology, Iligan City, Philippines. (Email jerson.orejudos@g.msuiit.edu.ph)

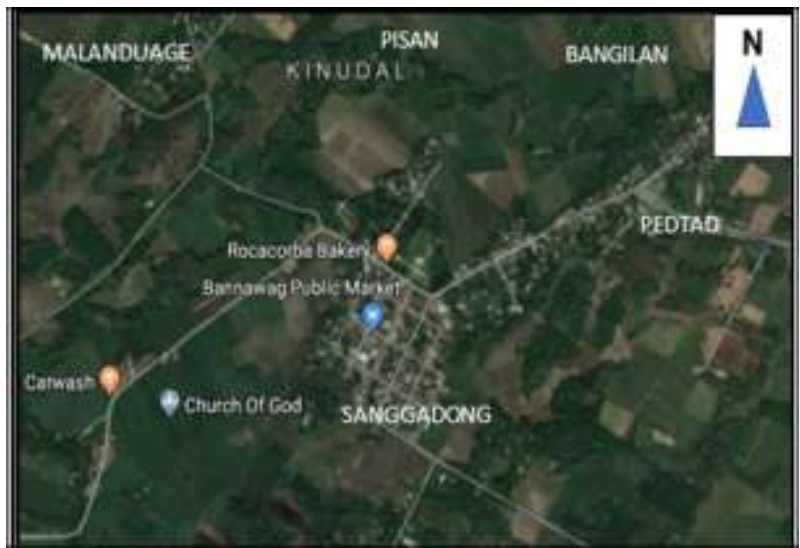

Fig. 1. Street Map of Bgy. Bannawag, Kabacan, Cotabato [16]

The pressure log monitor recorded a low pressure affecting the efficiency of the water supply to the concessionaires. In fact, the water utility reports [17] on the Non-Revenue Water (NRW) ranging from $3.83 \%$ (2016) to $8.62 \%$ (2017) although the number is quite mitigated in recent years to $5.48 \%$ (2018). There are many causes of low pressure in taps, some of which are water leaks in the main distribution lines that decrease the water pressure in taps [8]. However, leaks in the distribution mains are also caused by excessive pressures in pipes or aged pipes [3]

In response, the author proposes to use control valves to minimize the Non-Revenue Water associated with the occurrence of possible leaks and pipe bursts in the network. With the proper valve placement and combination determined through optimization technique, it is anticipated that this approach will help improve the KWD water distribution network with the optimized hydraulic pressures and guaranteed water supply. In this study, the researcher intends to address the problem by introducing a response methodology involving formulation of a novel algorithm to analyze the KWD pipe network.

\section{METHODS}

Actual survey (Fig. 2) of the water distribution network topology is performed and laid on the EPANET map. Data entries in the EPANET are taken from the KWD daily log monitor and actual water consumption. The results of the simulation characterized the existing hydraulic conditions of 


\section{OPTIMIZATION OF HYDRAULIC PRESSURES IN KABACAN WATER DISTRICT PIPE NETWORK USING H-NEWTON-RAPHSON TECHNIQUE}

the KWD pipe network. An optimization procedure using the h-Newton-Raphson technique previously presented by an author [14] is modified in this study, incorporating an open-source software for interfacing EPANET with MATLAB [17] and appropriately adjusted for convergence errors in case the hydraulic solver fails to converge. Experimentation of the placement of control valves which are treated as pipes in the virtual network follows using the proposed hydraulic simulator presented in this study.

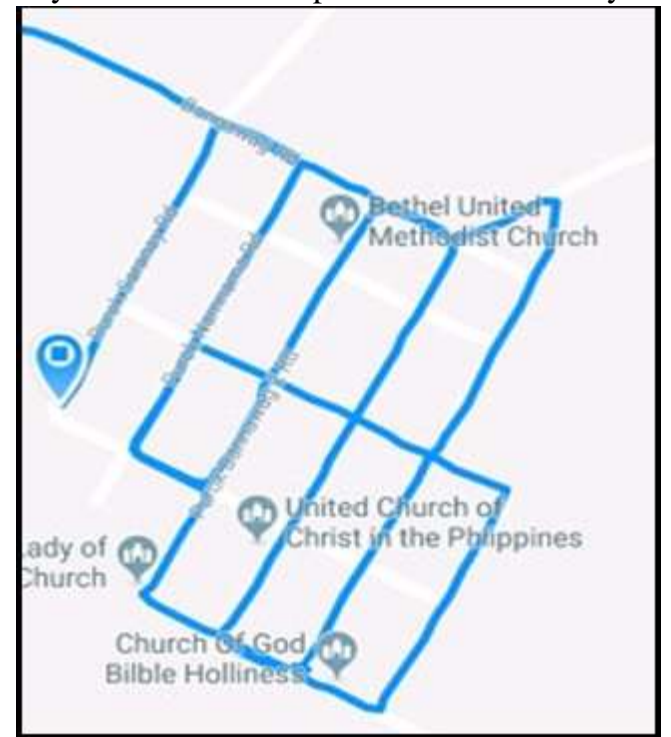

Fig. 2. Output of the tracked pipe route in Bgy. Bannawag, Kabacan, Cotabato

The matrix function is based on the methodology proposed by reference [12] and later improved by reference [14] for the nodal continuity equation adopted from the nodal pressure-outflow relationship equation.

$$
Q_{i-n}=\left(h_{i}-h_{n}\right) \frac{\pi D_{i n}^{2}}{2} \sqrt{2 g D_{\text {in }} \frac{\left|h_{i}-h_{n}\right|}{L_{i n}}} \log \left(\frac{\varepsilon}{3.7 D_{\text {in }}}+\right.
$$

$\left.\frac{2.51 v}{D_{i n} \sqrt{2 g D_{i n} \frac{\left|h_{i}-h_{n}\right|}{L_{i n}}}}\right)$

where:

$Q_{i \rightarrow n}=$ flow of the branch i-n $\left(\mathrm{m}^{3} / \mathrm{s}\right)$

$h_{i}=$ pressure head at node $\mathrm{i}$ (m col water)

$h_{n}=$ pressure head at node $\mathrm{n}$ ( $\mathrm{m}$ col water)

$D_{\text {in }}=$ internal diameter $(\mathrm{m})$

in = subscript for $\mathrm{D}$ indicating inside diameter

$L_{\text {in }}=$ length of the branch i-n (m)

$\varepsilon=$ roughness coefficient

$v=$ kinematic viscosity of water $\left(0.862 \times 10^{-6} \mathrm{~m}^{2} / \mathrm{s} @\right.$ $\left.27^{\circ} \mathrm{C}\right)$

$i=$ start node of every pipe length for all links

$j \quad=$ end node of every pipe length for all links

The nodal pressure-outflow relationship presented by reference [14] from conventional method shows that

$$
q_{n}^{\text {avl }}=\left\{\begin{array}{cl}
q_{n}^{\text {req }} & \text { if } h_{n} \geq h_{n}^{\text {des }} \\
q_{n}^{\text {req }}\left(\frac{h_{n}-h_{n}^{\text {min }}}{h_{n}^{\text {des }}-h_{n}^{\text {min }}}\right)^{\frac{1}{\lambda}} & \text { if } h_{n}^{\text {min }} \leq h_{n} \leq h_{n}^{\text {des }} \\
0 & \text { if } h_{n}^{\text {min }} \geq h_{n}
\end{array}\right.
$$

where:

$q_{n}^{a v l}=$ available nodal outflow at node $\mathrm{n}(\mathrm{cu} . \mathrm{m} / \mathrm{s})$

$q_{n}^{\text {req }}=$ required nodal demand at node $\mathrm{n}(\mathrm{cu} . \mathrm{m} / \mathrm{s})$

$h_{n} \quad=$ available head ( $\mathrm{m}$ col water)

$h_{n}^{\text {des }}=$ desired head to satisfy the nominal demand ( $\mathrm{m}$ col water)

$h_{n}^{\text {min }}=$ minimum allowable head at node $\mathrm{n}(\mathrm{m}$ col of water)

$\lambda=$ parameter of the power function (use $\lambda=2$ )

$\mathrm{n} \quad=$ represents the node in the network

The nodal equation of continuity is expressed as

$$
\begin{aligned}
& F_{n}=\sum_{i}^{I(n)}\left(( h _ { i } - h _ { n } ) \frac { \pi D _ { i n } ^ { 2 } } { 2 } \sqrt { 2 g D _ { i n } \frac { | h _ { i } - h _ { n } | } { L _ { i n } } } \operatorname { l o g } \left(\frac{\varepsilon}{3.7 D_{i n}}\right.\right. \\
& \left.\left.+\frac{2.51 v}{D_{i n} \sqrt{2 g D_{i n} \frac{\left|h_{i}-h_{n}\right|}{L_{i n}}}}\right)\right)-q_{n}^{a v l} \\
& =0, \forall n \in N
\end{aligned}
$$

where:

$F_{n} \quad=$ function representing the nodal equations of continuity at node $\mathrm{n}$

$I(n)=$ set of all branches including the n node

$q_{n}^{a v l}=$ available nodal outflow (cu.m/s)

$\mathrm{N}=$ total number of nodes

$\mathrm{g}=$ gravitational acceleration $\left(9.81 \mathrm{~m} / \mathrm{s}^{2}\right)$

Based on previous works [14], a classical method for solving the h-equations in looped pipe networks is the h-Newton-Raphson (N-R) method. At iteration $\mathrm{k}$, the N-R method is applied to the set of equations for the nodal hydraulic head $\mathrm{h}$ :

$$
\begin{aligned}
& \Delta h_{k}=-J_{k}^{-1} \times F_{K} \\
& h_{k+1}=h_{k}+\Delta h_{k}
\end{aligned}
$$

where

$$
\begin{gathered}
\Delta h_{k}=\left[\begin{array}{c}
\Delta h_{1} \\
\ldots \\
\Delta h_{n} \\
\ldots \\
\Delta h_{N}
\end{array}\right]_{k} \\
F_{k}=\left[\begin{array}{c}
F_{1} \\
\ldots \\
F_{n} \\
\ldots \\
F_{N}
\end{array}\right]_{k} \\
J_{k}=\left[\begin{array}{lllll}
J_{11} & J_{12} & \ldots, & J_{1 n}, \ldots & J_{1 N} \\
J_{n 1} & J_{n 2} & \ldots, & J_{n n}, \ldots & J_{n N} \\
J_{N 1} & J_{N 2} & \ldots, & J_{N n}, \ldots & J_{N N}
\end{array}\right]
\end{gathered}
$$


where:

$k=$ number of iterations in the Newton-Raphson method

$h_{k}=$ assumed value for initial hydraulic head at each node (m col water)

$\Delta h_{k}=$ correction of the total hydraulic head (m col water)

$h_{k+1}=$ vector for the correction of nodal head

$F_{k} \quad=$ vector of all $F_{n}$ at iteration $\mathrm{k}$

$J_{k}=$ Jacobian matrix of $F_{k}$ at iteration k

$J_{11} \quad \ldots J_{n N} \ldots J_{N N}=$ partial derivatives of functions $\mathrm{F}$ of the Jacobian matrix from $\mathrm{nN}$ to $\mathrm{NN}$

There are three virtual networks with four possible control valve placements in the network chosen based on the hydraulic analysis report of the EPANET run. The basis for selection of valve placement is the occurrence of critical pressures $h_{n}>h_{\max }$ or $h_{n}<h_{\min }$, where $h_{n}$ is the actual pressure in the network. Each simulation is performed for each of the three virtual networks, with four different valve placements and four valve settings that comprise a total of 48 network models. The optimization results are compared utilizing an elimination process based on the set criteria.

and

$$
q_{\text {opt }}>q_{\text {des }}
$$

$$
h_{\min }<h_{\text {opt }}<h_{\max }
$$

where:

$q_{\text {opt }}$ is the optimized nodal outflow $\left(\mathrm{m}^{3} / \mathrm{s}\right)$

$q_{\text {des }}$ is the desired nodal outflow $\left(\mathrm{m}^{3} / \mathrm{s}\right)$

$h_{\text {min }}$ is the minimum hydraulic head $(45.5 \mathrm{~m})$

$h_{\text {opt }}$ is the optimized hydraulic head (m)

$h_{\max }$ is the maximum hydraulic head $(50.0 \mathrm{~m})$

The safest pressure $h_{\min }<h_{\text {opt }}<h_{\max }$ obtained from the simulated networks is chosen as the best optimized network model for Zone B WDN of the Kabacan Water District. In case all results give the desired pressures, then the selection of the best simulated model is based on the quantity of flow, or

$$
q_{\text {opt }}>q_{\text {des }}
$$

where $q_{o p t}$ is the optimized nodal outflow and $q_{\text {des }}$ is the desired nodal outflow.

The formulated numerical model is also validated using comparison of results with the analytical method, EPANET simulation results and the methods of reference [12], [13], [14].

\section{RESULTS AND DISCUSSION}

As the consumption at night approaches zero, excessive pressures are observed as shown in Fig. 3. Many nodes are affected by the large pressures $(>100 \mathrm{~m})$ as indicated by the red color in the pressure contour plot. In a study presented by reference [15], similar contour map of their EPANET model was plotted which they presumed that the excessive pressure was associated with the excessive loss of water. This loss in the system pressure can result in a water system with reduced hydraulic capacity due to high head losses. These are the critical points in the network where control valves are needed.

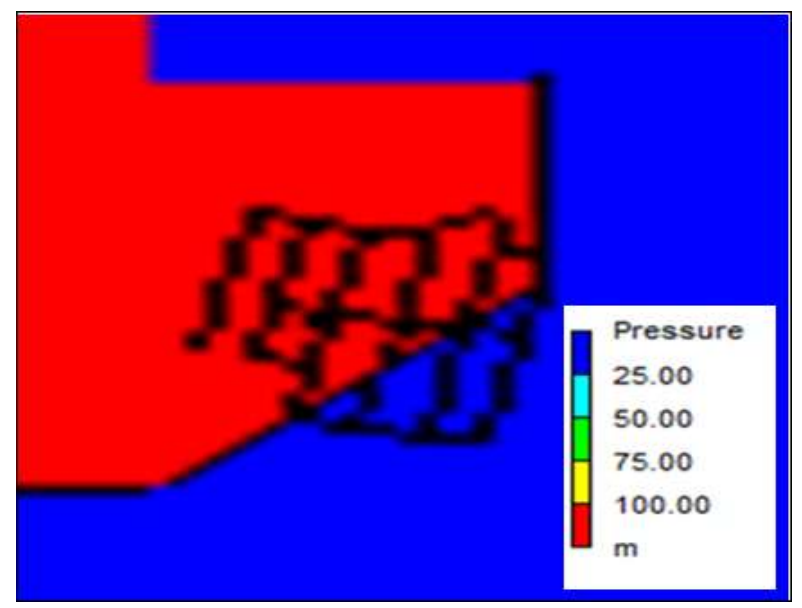

Fig. 3. EPANET Contour plot pressure at 0:00 hours

The proposed method is applied to the three networks adopted from previous works [14] and [3] with interacting valves, namely: Network 1 with Pressure Reducing Valve and Flow Control Valve connected in series (PRV-FCV in series); Network 2 with Pressure Reducing Valve and Pressure Sustaining Valve connected in series (PRV-PSV in series); and Network 3 with two Pressure Reducing Valves connected in parallel (PRV-PRV in parallel). The simulations are performed using the numerical model written by the author. The program formulated in this study is modified and tailored to the various conditions required by each valve placement, so that there are 16 major adjustments made in equations 2.1 and 2.3, including the valve sizes and the pipe lengths for each network, or a total of 48 programs (h_Optimization.m). For the network analyses, the calculations were conducted at Tolerance $=10^{-13}$ for all the algorithms.

Fig. 4 below shows a comparison of the nodal outflow of the best models selected from the three networks. The network demand is fully satisfied by the two proposed models namely net_2c and net-3a. In terms of the pressure head (Fig. 5) and hydraulic head (Fig. 6), networks 2c (PRV-PSV) and 3a (PRV-PRV) showed favorable outcomes than net01c (PRV-FCV). It can be deduced that said combination of valves are effective in maintaining the hydraulic integrity of the pipe network. The usual design procedures require minimum nodal pressures to satisfy nodal outflows [19].

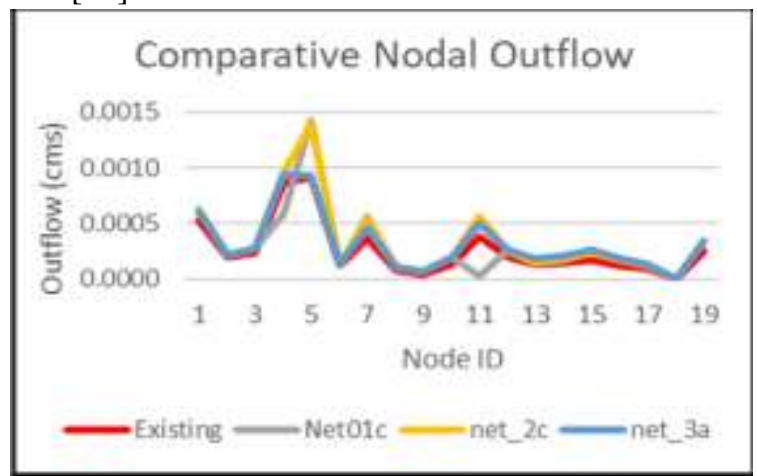

Fig. 4. Comparative nodal outflows of the 3 best optimized networks 


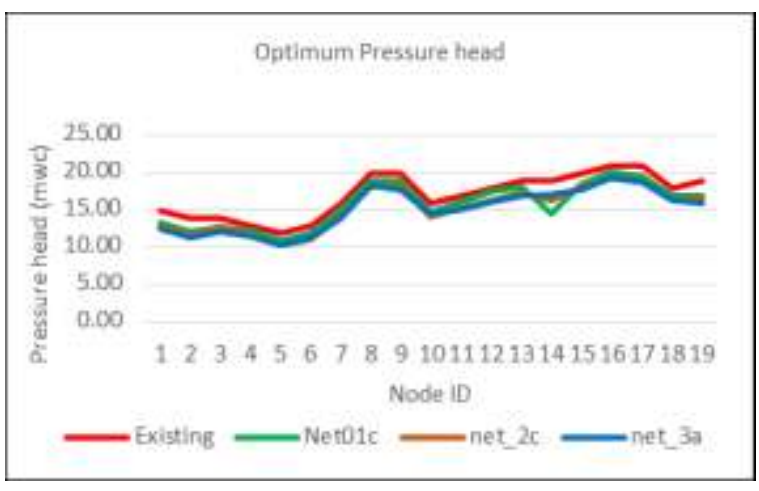

Fig. 5. Comparative pressure heads of the 3 best optimized networks

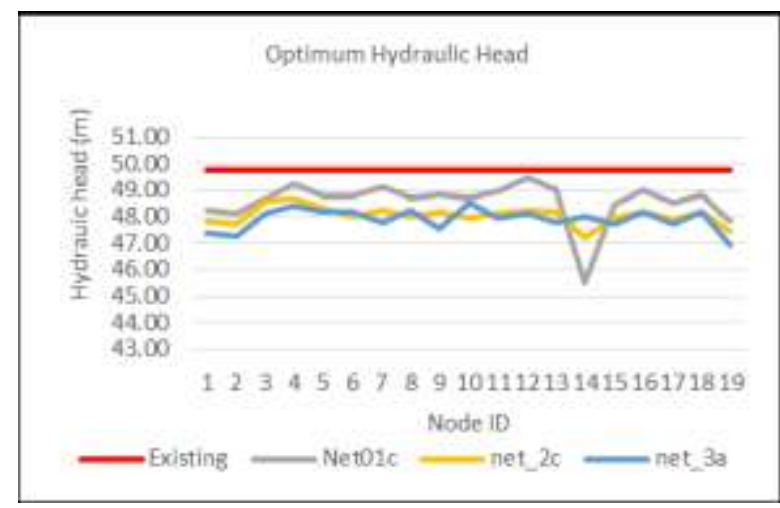

Fig. 6. Comparative hydraulic heads of the 3 best optimized networks

In terms of valve sizes, network $3 a$ has the least size (56 $\mathrm{mm}$ ) which is economically advantageous (Table 1), thus, a better functional option. Consequently, the best optimized network is the combination of PRV-PRV placed in parallel (Fig. 7) on links where the ground elevation is lower. Compared with the existing conditions, the optimized model showed an increase in the nodal outflows for all nodes in the network, particularly in node 5 (Table 1) where the bulk of the household consumption is greatest. The valve diameters are adjusted to fit the link size, e.g., for network 1, PRV and FCV diameters are set to 71,73,75, and $78 \mathrm{~mm}$ when connected to a $78 \mathrm{~mm}$ pipe. The corresponding pressure heads (PRV) and outflows (FCV) are calculated by the proposed numerical model, e.g. 17.19, 17.18, 17.20, and $17.21 \mathrm{mwc}$ for the four PRV diameters; and $0.03963 \mathrm{lps}$ for the four FCV diameters. These valve sizes are applied only to one valve placement, particularly on a pipe size of $78 \mathrm{~mm}$ for Network 1 (PRV-FCV in series). There are four valve placements for each virtual network, with the assigned four valve sizes for each placement in the network, thus, a total of 16 different simulations for each virtual network is done.
Table 1: Showing partial results of nodal outflows of the selected network models

\begin{tabular}{|c|c|c|c|c|}
\hline \multicolumn{2}{|c|}{$\begin{array}{c}\text { Valve } \\
\text { combination }\end{array}$} & PRV-FCV & PRV-PSV & PRV-PRV \\
\hline \multicolumn{2}{|c|}{ Proposed network } & Net01c & net $2 c$ & net 3a \\
\hline \multicolumn{2}{|c|}{$\begin{array}{c}\text { Valve } 1 \text { Diam } \\
\text { (mm) }\end{array}$} & 85 & 102 & 56 \\
\hline \multicolumn{2}{|c|}{$\begin{array}{c}\text { Valve } 2 \text { Diam } \\
\text { (mm) }\end{array}$} & 85 & 102 & 56 \\
\hline \multicolumn{2}{|c|}{ No. of Iteration } & 22 & 23 & 17 \\
\hline $\begin{array}{l}\text { Nod } \\
\text { e No. }\end{array}$ & Existing & \multicolumn{3}{|c|}{ Optimized Nodal Outflows $\left(\mathrm{m}^{3} / \mathrm{s}\right)$} \\
\hline 1 & $\begin{array}{r}0.000518^{7} \\
0\end{array}$ & $\begin{array}{r}0.0006269 \\
7\end{array}$ & $\begin{array}{r}0.0006146 \\
0\end{array}$ & $\begin{array}{c}0.0006007 \\
6\end{array}$ \\
\hline 2 & $\begin{array}{r}0.0001926 \\
6\end{array}$ & $\begin{array}{r}0.0002200 \\
2\end{array}$ & $\begin{array}{r}0.0002151 \\
4\end{array}$ & $\begin{array}{c}0.0002096 \\
8\end{array}$ \\
\hline 3 & $\begin{array}{r}0.0002371 \\
2\end{array}$ & $\begin{array}{r}0.0002793 \\
3\end{array}$ & $\begin{array}{r}0.0002773 \\
5\end{array}$ & $\begin{array}{c}0.0002704 \\
7\end{array}$ \\
\hline 4 & $\begin{array}{r}0.0008595 \\
6\end{array}$ & $\begin{array}{r}0.0005941 \\
b\end{array}$ & $\begin{array}{r}0.0009579 \\
5\end{array}$ & $\begin{array}{c}0.0009419 \\
7\end{array}$ \\
\hline 5 & $\begin{array}{r}0.0009188 \\
4\end{array}$ & $\begin{array}{r}0.0014241 \\
3 \\
\end{array}$ & $\begin{array}{r}0.0014006 \\
3 \\
\end{array}$ & $\begin{array}{c}0.0009312 \\
7\end{array}$ \\
\hline
\end{tabular}

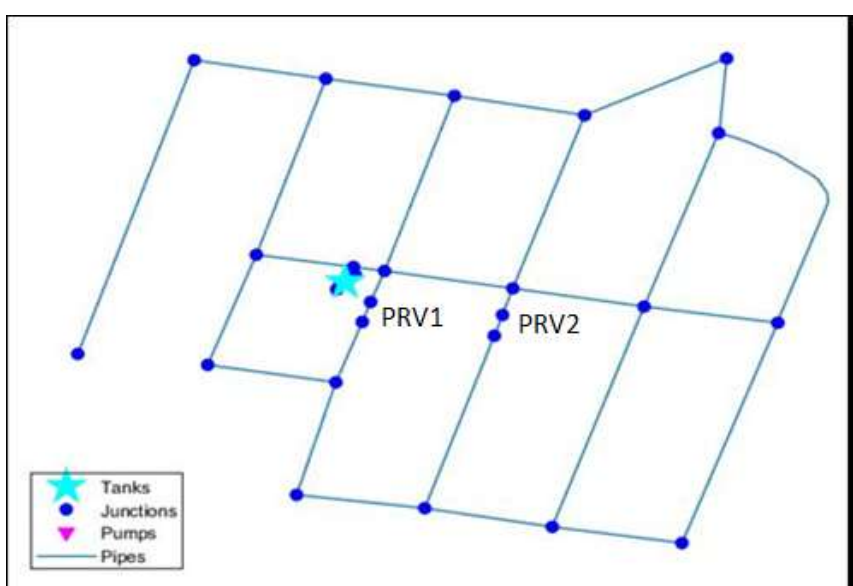

Fig. 7. Valve placement for network 3a (PRV-PRV). Pump located near the tank

As expected, the pressure heads at lower elevation nodes (16 \& 17) are greatest at $20 \mathrm{mwc}$, albeit in the optimized network, the pressure heads in these nodes significantly dropped, with node 17 receiving the greatest impact of pressure head reduction (Fig. 5). Also, at an optimum hydraulic head (Fig. 6), these critical nodes $(5,16,17)$ are doing well as evidenced of increase in nodal outflows illustrated in Fig. 5. The pressure head in all nodes in the optimized network did not fall below 3.0 mwc but settled at 10 mwc at the highest ground level (node 5). The placement of the PRV-PRV connected in parallel makes the hydraulic capacity of the KWD network more efficient in terms of satisfying the demands in all tapping points at an optimum pressure. Besides, the pipes with critical pressures prior to the optimization are protected from possible leaks or breakages.

\subsection{Validation of the Numerical Model}

To validate the reliability of the proposed numerical model, a sample network (Fig. 8) from the published work 
[14] is used in the simulation to compare results. Using analytical calculations, the observed data show a very close series trend for the $\Delta h$ (equation 2.4) values in Fig. 9. Although the analysis is terminated in the $1^{\text {st }}$ iteration procedure, the author is confident that the proposed numerical model is consistent with the results when the error correction for delta_h is applied to equations 2.1 to 2.3 and repeated until it reaches the tolerance limit.

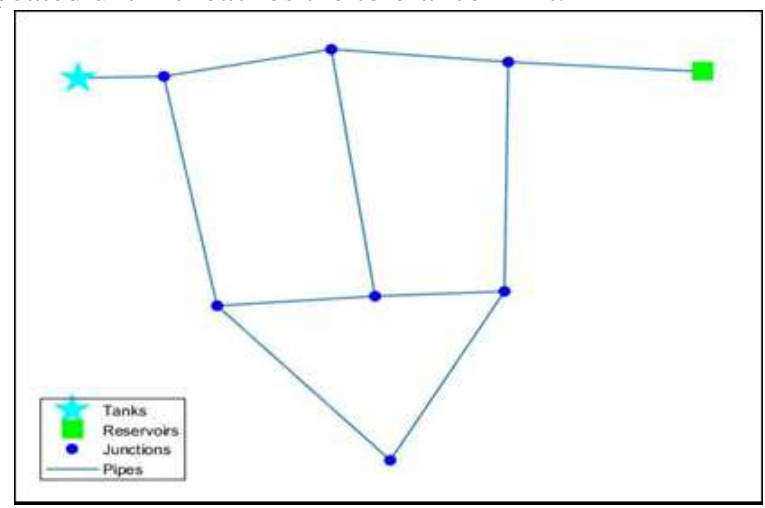

Fig. 8. Sample network

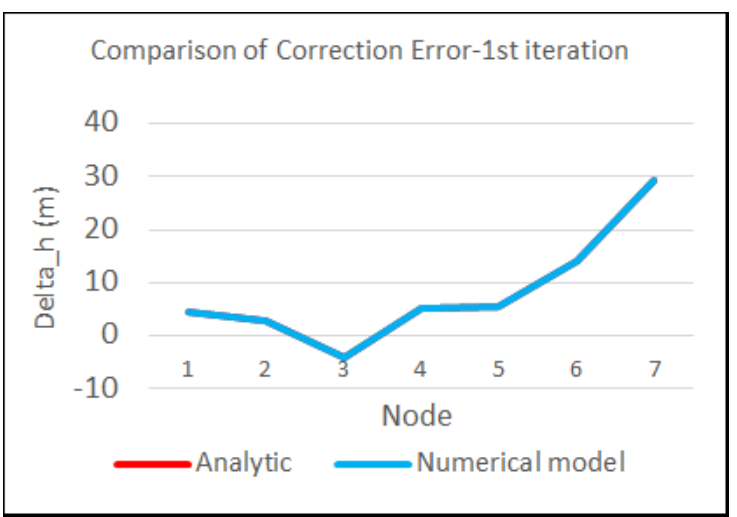

Fig. 9. Comparative delta_h values

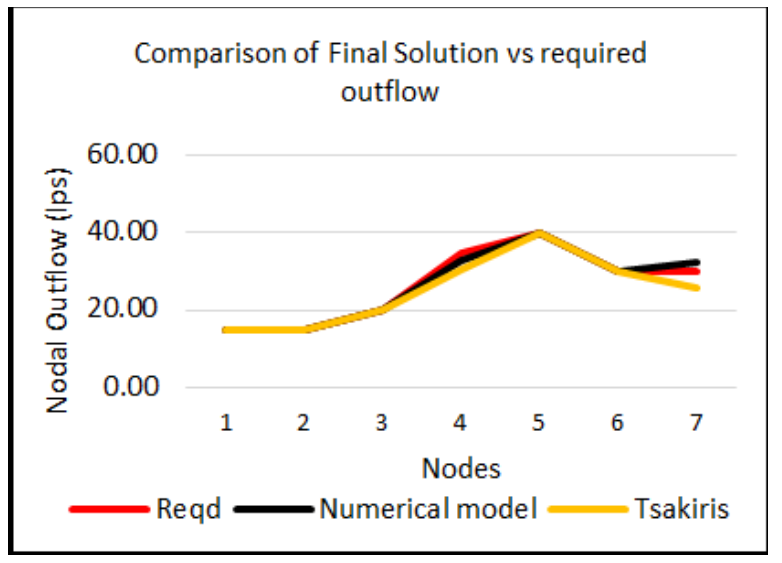

Fig. 10. Comparative nodal outflow optimum solution

Comparing the simulation results with the discussed paper [14], the optimum solution for the nodal outflows also showed a consistent trend (Fig. 10). The Computational Error

(CE) is also determined using the equation in the published work of the above author [14] written as

$$
\left.C E=\left(\sum_{n=1}^{N}\left(F_{n}\right)^{2}\right)^{\frac{1}{2}}\right]_{k}
$$

which obtained a near zero result of 4.98E-15. Finally, the optimum solutions (Fig. $11 \&$ 12) for the network model 3a (PRV-PRV in parallel) obtained from the proposed hydraulic solver followed the same trend with the simulated results from EPANET. As observed, the optimized model illustrates a lower pressure head when all the tapping points in the network is fully satisfied with higher nodal outflows than the existing KWD pipe network. Considering the above analysis, one can be confident to use the numerical model formulated by the author to analyze looped pipe networks.

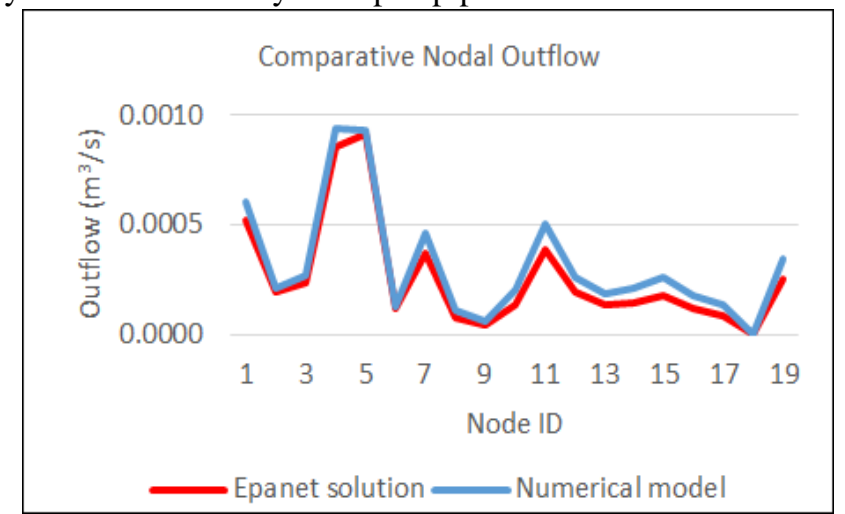

Fig. 11. Comparative nodal outflow optimum solution of EPANET and the proposed numerical model

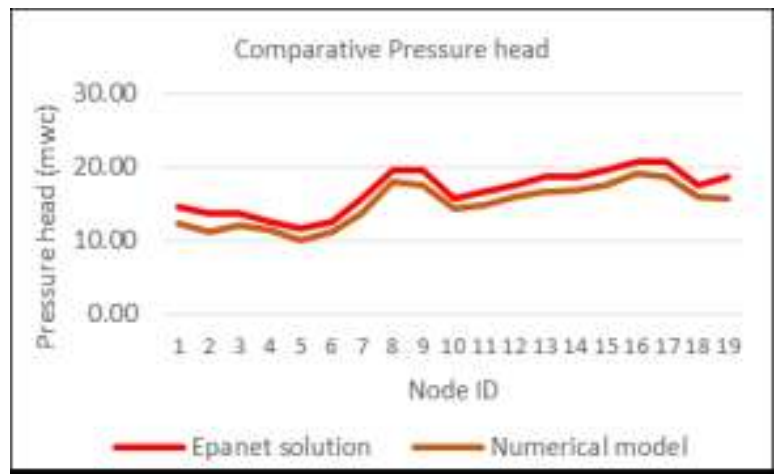

Fig. 12. Comparative pressure head optimum solution of EPANET and the proposed numerical model

\section{CONCLUSIONS}

Prior to the method of optimization introduced in this paper, the sufficiency of the water system of the KWD pipe network is ambiguous considering its vulnerability in terms of its hydraulic capacity, viz: (1) failure to maintain the safe operating pressure leading to inadequate water supply in the network during peak hours; and (2) the danger for possible distribution main breaks due to high pressures during off-peak hours. The evidence of low pressures due to excessive head losses leads to pressure transients $(<7.0 \mathrm{mwc}$ or $<10 \mathrm{psi}$ ) during the daytime. On the other hand, the large pressures at night time can cause or worsen wear on valves and fittings which eventually add up to the problem on leakages or to the extent of exposure to main breaks. As water leakage losses increase, the hydraulic pressure in a water distribution system also increases [19]. The algorithm written by the author proved to be efficient in determining the best solution to optimize the KWD network, and can work even in 


\section{OPTIMIZATION OF HYDRAULIC PRESSURES IN KABACAN WATER DISTRICT PIPE NETWORK USING H-NEWTON-RAPHSON TECHNIQUE}

larger and complex networks. The impact of the proposed methodology resulted in a simpler and more accurate algorithm for analyzing looped distribution systems using the method of reference [4] where all valves are modelled as pipes; and the contributions of reference [14].

\section{ACKNOWLEDGMENTS}

I would like to thank the KWD family for their assistance with the collection of my data. My special thanks are also extended to the staff of MPDC Kabacan and BLGU-Bannawag. I am particularly grateful for the assistance given by Dr. Jerson N. Orejudos, Dr. Glen A Lorenzo, Dr. Rodel D. Guerrero and Dr. Jonathan C. Maglasang. Most especially, my grateful appreciation for the perpetual support of my husband. Above all, I give a million thanks to the Almighty Father who made this endeavor possible.

\section{REFERENCES}

1. Abraham E., Blokker, E.J.M. \& Stoianov, I. (2017) Network analysis, control valve placement and optimal control of flow velocity for self-cleaning water distribution systems. Procedia Engineering 186 (2017) 576-583.

2. Fontana N., Giugni, M., ᄀGlielmo, L., Marini, G. \& ᄀ Verrilli, F. (2017). A lab prototype of pressure control in water distribution networks. IFAC Papers Online, 50-1 (2017) 15373-15378.

3. Gençoğlua G. \& Merzib N. (2017). Minimizing excess pressures by optimal valve location and opening determination in water distribution networks. XVIII International Conference on Water Distribution Systems Analysis, WDSA 2016. Procedia Engineering 186 (2017) 319-326.

4. Gorev N.B., Gorev, V.N., Kodzhespirova, I.F., Shedlovsky, I.A. \& and Sivakumar, P. (2018). Simulating control valves in water distribution systems as pipes of variable resistance. Technical note. Journal of Water Resources Planning and Management, 144(11): 06018008.

5. Jowitt, P. \& Xu, C. (1990). Optimal valve control in water distribution networks. Journal of Water Resources Planning and Management, Vol. 116, No. 4, ASCE ISSN 0733-9496/90/0004-0455.

6. Piller, O. \& van Zyl, J. E. (2014). Modeling control valves in water distribution systems using a continuous state formulation. Journal of Hydraulic Engineering. DOI: 10.1061/(ASCE)HY.1943-7900.0000920

7. Reis L. F. R., Porto, R. M. \& Chaudhry, F. H. (1997). Optimal location of control valves in pipe networks by genetic algorithm. Journal of Water Resources Planning and Management. Vol. 123, No. 6, November-December 1997.

8. Samir N., Kansoh, R., Elbarki, W. \& Fleifle, A. (2017). Pressure control for minimizing leakage in water distribution systems. Alexandria Engineering Journal. http://dx.doi.org/10.1016/j.aej.2017.07.008.

9. Giustolisi, O., \& Laucelli, D. (2011). Water distribution network pressure-driven analysis using the enhanced global gradient algorithm (EGGA). Journal of Water Resources Planning and Management, 137, 498-510.

10. Shirzad, A., Massoud Tabesh, M. \& Atayikia, B. (2017). Multi-objective optimization of pressure dependent dynamic design for water distribution networks. Water Resour Manage.

11. Siew, C. \& Tanyimboh, T.T. (2012). Pressure-Dependent EPANET extension. Water Resource Management. 26:
1477.

12. Spiliotis M. \& Tsakiris G, (2011). Water distribution system analysis: Newton-Raphson method revisited. Journal of Hydraulic Engineering, 2011.137:852-855.

13. Spiliotis, M., \& Tsakiris, G. (2012). Water distribution network analysis under fuzzy demands. Civil Engineering and Environmental Systems, 29, 107-122.

14. Tsakiris, G. \& Spiliotis, M. (2014). A Newton-Raphson analysis of urban water systems based on nodal head-driven outflow. European Journal of Environmental and Civil Engineering, Vol. 18, No. 8, 882-896.

15. Alves, Z., Muranho, J., Albuquerque T., Ferreira, A. (2014). Water distribution network's modeling and calibration. A case study based on scarce inventory data. Procedia Engineering 70 (2014) 31-40.

16. Google Maps. Bgy. Bannawag, Kabacan, Cotabato. Online].

Available: https://www.google.com/maps/@7.1537241,124.863949 $4,2885 \mathrm{~m} /$ data $=! 3 \mathrm{~m} 1 ! 1 \mathrm{e} 3$

17. KWD, 2018. Documents from KWD files.

18. Eliades, D. G., Kyriakou, M., Vrachimis, S., \& Polycarpou, M. M. (2016). "EPANET-MATLAB Toolkit: An open-source software for interfacing EPANET with MATLAB", in Proc. 14th International Conference on Computing and Control for the Water Industry (CCWI), The Netherlands, Nov 2016, p.8.

19. Swamee, P. K. \& Sharma, A. K. (2008). Design of Water Supply Pipe Networks. John Wiley \& Sons, Inc., Hoboken, United States. ISBN13 9780470178522.

\section{MAIN AUTHOR PROFILE}

Name: 'Ma. Dely P. Esberto

Address: 766 Roxas St.,Kabacan, Cotabato, Philippines Birth day: 'Feb. 17, 1965

Birth place: `Molave, Zamboanga del Sur

Affiliation: Mindanao State University- Iligan Institute of Technology, Iligan City, Philippines

Position: Student

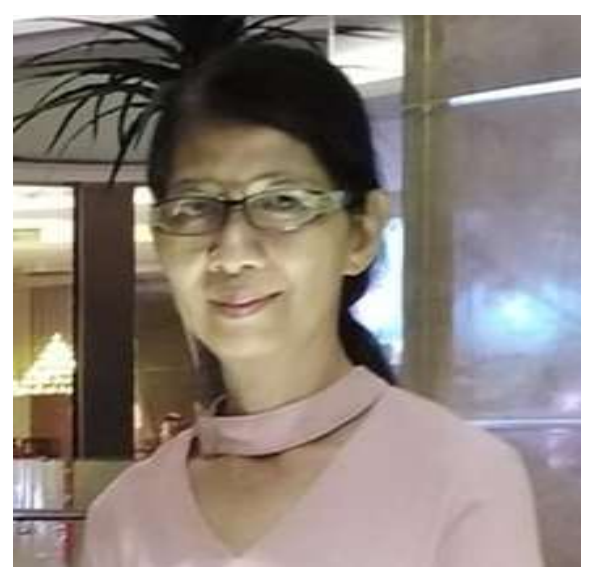

